\title{
FEATURE \\ Examining the paired comparison method approach for determining soil organic carbon sequestration rates
}

\author{
Kenneth R. Olson, Mahdi Al-Kaisi, Rattan Lal, and Birl Lowery
}

$\mathrm{n}$ recent years, researchers have published soil organic carbon (SOC) sequestration rates for conventional tillage (CT) and no-tillage (NT) systems. Determining SOC sequestration is a very challenging and complex issue, especially when it involves highly dynamic systems such as climate and agroecosystems. The monitoring of soil organic matter (SOM) change is important to determine the sustainability of soil health and productivity as we face some daunting challenges in climate change. Improvement in SOC sequestration is an integrative process of atmosphere-plant-soil that has been widely documented in the literature (e.g., Franzluebbers 2010; Johnson et al. 2005; Liebig et al. 2005; Franzluebbers and Follett 2005; West and Post 2002; Lal 1999). However, most of the documented SOC sequestration rates have been determined using the "paired comparison method," which refers to the comparison of two tillage systems to each other with the absence of the pretreatment baseline for SOC stocks measured prior to the implementation of such tillage treatments. This article critically reviews the paired comparison approach that has been used by many scientists in determining soil $\mathrm{C}$ sequestration rates. Paired tillage treatments, with one treatment such as moldboard plow (MP) or any CT selected as a baseline or control, have been used to determine SOC sequestration rate. Often the paired comparison between tillage systems is based on only one-time soil sampling near the end of a long-term study to determine the average

Kenneth R. Olson is a professor of soil science, Department of Natural Resources and Environmental Sciences, College of Agricultural, Consumer, and Environmental Sciences, University of Illinois, Urbana, Illinois. Mahdi At-Kaisi is a professor of agronomy, Department of Agronomy, College of Agriculture, lowa State University, Ames, lowa. Rattan Lal is a professor of soil science and director of the Carbon Management and Sequestration Center, The Ohio State University, Columbus, Ohio. Birl Lowery is a professor in the Department of Soil Science, University of Wisconsin-Madison. rate of SOC sequestration. This approach raises significant questions about the validity of the results of SOC sequestration estimation. The use of this approach by some scientists is based on assumptions that the baseline tillage treatment (CT) at the end of a study is at a steady state and that it has the same SOC stocks it had prior to the tillage treatment implementation. Based on that assumption, any increase in SOC stocks of the comparison treatment (e.g., NT) above the baseline treatment (e.g., CT) would represent the amount of SOC sequestered. The comparison approach is often used due to a lack of measured pretreatment SOC stock (Olson 2010). Without such pretreatment SOC stock measurements, the SOC sequestration magnitude and rate cannot be verified (Olson 2010; Sanderman and Baldock 2010).

As apparent in table 1, researchers have published SOC sequestration rates that can be achieved by simply switching from MP or CT to NT based on the paired comparison approach. This may be true. However, there is a growing body of scientific literature related to the contribution of agronomic best management practices to sequester SOC (Huggins et al. 2007; Luo et al. 2010; Kumar et al. 2012, Lyons et al. 1997; Janzen 2006; BlancoCanqui and Lal 2008; Casta Junior et al. 2013) that suggests that the SOC seques- tration rates in table 1 may be too high. Other researchers (Olson 2010; Baker et al. 2007; Sanderman and Baldock 2010; Sanford et al.2012) found that SOC stocks declined from pretreatment levels even with long-term NT studies under soilspecific conditions, such as conversion of prairie to agricultural land, drainage, aeration, tillage, and erosion. There is evidence that NT systems in corn (Zea mays L.) and soybean (Glycine max L.) rotations can lose SOC as well because any cropping system is dynamic and fresh $\mathrm{C}$ is subject to decomposition and loss. Results from those studies have shown that MP and NT systems are actually losing SOC stocks over time, but often NT systems lose SOC stocks at a slower rate than that of the MP system. This SOC loss will not diminish the value of NT systems in annual cropping systems and the associated ancillary benefits provided by NT to improve soil health, SOM content, erosion control, and energy savings. However, to increase the effectiveness of $\mathrm{NT}$ as alternative to $\mathrm{CT}$ systems that accelerate soil quality deterioration and SOM loss in particular, the inclusion of cover crops, small grains, and forages with NT can contribute to the increase in SOC stocks in the range of 0.30 to $0.50 \mathrm{t} \mathrm{C} \mathrm{ha}^{-1} \mathrm{y}^{-1}$ (300 to $500 \mathrm{lb}$ $\mathrm{ac}^{-1} \mathrm{yr}^{-1}$ ) (Olson et. al. 2014). Furthermore, the adoption of better methods of calculating SOC sequestration rate as a result of

\section{Table 1}

Published worldwide, United States, and regional United States soil organic carbon (SOC) sequestration, retention, or net storage rates for a switch from moldboard or conventional tillage to no-tillage.

\begin{tabular}{lll}
\hline $\begin{array}{l}\text { Worldwide, USA, and } \\
\text { USA regional }\end{array}$ & $\begin{array}{l}\text { SOC sequestration or } \\
\text { retention rate }\left(\mathbf{M g ~ C ~} \mathbf{~ h a}^{-\mathbf{1}} \mathbf{~}^{\mathbf{- 1}}\right)\end{array}$ & Source reference \\
\hline Worldwide & $0.48 \pm 0.13$ & West and Post (2002) \\
Humid climates & 0.22 & Six et al. (2004) \\
Arid climates & 0.10 & Six et al. (2004) \\
\hline USA & 0.50 & Lal et al. (1998) \\
North central & $0.48 \pm 0.59$ & Johnson et al. (2005) \\
Northwest & $0.27 \pm 0.19$ & Liebig et al. (2005) \\
Southeast & $0.45 \pm 0.04$ & Franzluebbers (2010) \\
Northeast & $-0.07 \pm 0.27$ & Gregorich et al. (2005) \\
Southwest & $0.30 \pm 0.21$ & Franzluebbers and Follett (2005)
\end{tabular}


switching to NT may provide more credible data. The use of pretreatment baseline SOC measurement is crucial in evaluating the effectiveness of NT or any other conservation practice. The SOC loss associated with any tillage system is governed by the stability of the system. However, the benefits added to soil stability by having more crop residues on soil surface as in NT can improve soil physical properties in addition to improving SOC stocks. On the other hand, in the case of CT, SOC losses are more significant due to water and wind erosion.

In agricultural cropping systems, NT is often superior to $\mathrm{CT}$ systems in retention of SOC despite the potential soluble C loss to leaching as result of improvement in hydrological and physical soil properties. In addition, NT can enhance soil quality indicators such as aggregate stability, microbial biomass $\mathrm{C}$, and a range of physical properties. For SOC sequestration to occur based on the proposed SOC sequestration definition (Olson et al. 2014) as a result of a treatment applied to a land unit, all of the SOC sequestered must have originated from the atmospheric carbon dioxide $\left(\mathrm{CO}_{2}\right)$ pool and be transferred into the soil humus through the unit plants, plant residues, and other organic solids. The amount of SOC present in the soil humus near the end of the study must be greater than those of the sequestration. The other consideration that pretreatment SOC stocks in the same land is often overlooked is the sampling depth. unit to satisfy the proposed C sequestra- In general, soil under NT on sloping and tion concept. To unequivocally demonstrate eroding sites retains more SOC in the surthat SOC sequestration at a specific site has face 0 to $5 \mathrm{~cm}(0$ to $2 \mathrm{in}$; figure 1$)$ or 0 occurred, a temporal increase must be doc- to $15 \mathrm{~cm}$ (0 to $6 \mathrm{in})$ as compared to that umented relative to pretreatment SOC and under MP as a result of less soil disturlinked with attendant changes in soil prop- bance, less soil erosion, less decomposition erties and ecosystem services and functions rate, and less loss or transport of SOC-rich (Olson et al. 2014).

\section{REVIEW AND ANALYSIS OF PUBLISHED STUDIES} After examining numerous original research analyzed to a depth equivalent to the root and summary papers, 120 papers on all sides zone, depending on the cropping system. of the SOC sequestration, storage, retention, In doing so, the NT subsurface layer may and loss issues were selected for review and lose SOC stock over time as compared to analysis (Olson et al. 2014). Critical review the surface layer (figure 2). This loss may of the available literature shows that the dif- be attributed to potential leaching of solference between the NT and CT treatments uble C as the water infiltration rate and at the end of a long-term study using the preferential flow improves under NT.

paired plot approach is only a measure of net There are a number of reasons for the SOC storage difference between the two inconsistency for different methods of treatments and does not represent a SOC determining SOC sequestration, includ- ing differences in the definition of SOC sequestration used by different researchers. In accordance with the proposed definition, "the process of transferring $\mathrm{CO}_{2}$ from the atmosphere into the soil of a land unit through unit plants, plant residues, and other organic solids, which are stored or retained in the unit as part of the SOM or humus" (Olson et al. 2014), some of the reported SOC sequestration results are questionable. For these estimates to be valid, the management practices must lead to an increase in the net SOC from a pretreatment baseline measurement (Olson 2013). Any increase in soil $\mathrm{C}$ that is not directly originating from the atmosphere (from outside the land unit) does not meet the proposed $\mathrm{C}$ sequestration definition. These external inputs may include organic fertilizers, manure, plant residues, topsoil, or natural input processes such as soil erosion and sediment-rich $\mathrm{C}$ deposition on a soil located on a lower landscape position or in a waterway. 
The application of C-rich amendments or the natural deposition of SOC-rich sediment (Olson 2013) from outside the land unit needs to be accounted for when determining SOC sequestration. The land unit could be a plot, plot area, parcel, tract, field, farm, landscape position, landscape, wetland, forest, or prairie with defined and identified boundaries (Olson 2013). The definition of SOC sequestration proposed here requires that the land unit used has specified boundaries and that $\mathrm{C}$ gains from the atmosphere to the soil humus are based on $\mathrm{C}$ inputs from the land unit plants, roots, and their residues only. Any loading of external C-rich amendments, such as manure and organic fertilizers, must be accounted for in analysis and should be deducted from the claimed SOC sequestration. The C loading on a land unit would most likely increase the amount of $\mathrm{CO}_{2}$ released from the land unit during the decomposition process to the atmosphere even if some additional humus formation were to occur on the land unit as a result of the $\mathrm{C}$ loading. These amendment cases illustrate the need for specifying the land unit and origin of the $\mathrm{C}$ sources in order to accurately measure the change in SOC derived from the atmosphere. Other methodological factors that could lead to errors in reporting SOC sequestration rates include

- using inappropriate experimental design;

- sampling surface layers only;

- omitting measurements of soil bulk density;

- ignoring $\mathrm{C}$ addition from amendments applied to the plots from external sources;

- using different SOC analysis laboratory methods over the long-term study;

- ignoring the effects of soil erosion;

- ignoring the transport and deposition of SOC-rich sediments to the experimental plots;

- disregarding spatial variability during the sampling scheme; and

- not including time series sampling to determine rate of change over the study period.

More often than not, SOC stocks have not remained at a steady state during the last 50 years as a result of aeration, drainage, tillage, disturbance, erosion, deposition, lack of extended crop rotations, lack of organic amendment use, erosion, and lack

\section{Figure 2}

Soil organic carbon (SOC) stocks of the pretreatment baseline and after 20 years on the moldboard plow (MP) and no-tillage (NT) plots in the o to $75 \mathrm{~cm}$ surface layer.

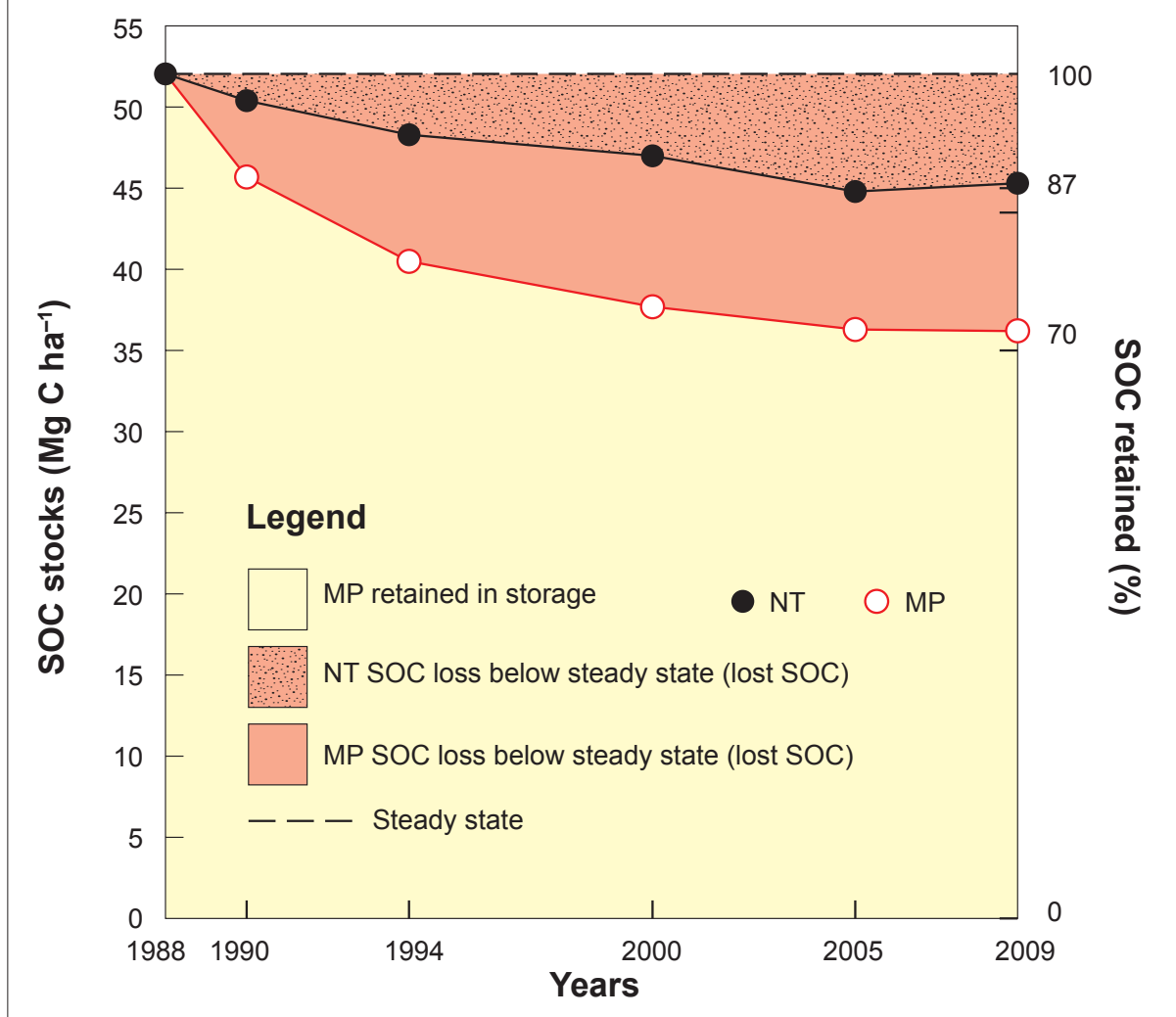

of cover crops; these factors can all result in reduced SOC stocks.

Admittedly, it takes significant amount of time (20 to 50 years) to design and manage a long-term study. There are few long-term studies that had all the required soil property data collected for the root zone or a depth of 1 to $2 \mathrm{~m}$ (3.3 to 6.6 $\mathrm{ft})$ prior to tillage treatment establishment and that were sampled frequently during and at the end of the study. One such tillage study was conducted at University of Illinois's Dixon Springs Agricultural Center. The plot area is a part of the North Central Region Soil Erosion and Productivity Committee study. It is sited on a Grantsburg soil with a fragipan at 75 $\mathrm{cm}$ depth (30 in), moderately eroded, on 6\% slope gradient (Olson 2010).

The accuracy of determining SOC sequestration also depends on the method used. Olson et al. (2014) used both the paired comparison method and the pretreatment SOC method for the same data collected from this long-term tillage experiment. The results of comparison showed that the paired method (NT vs. $\mathrm{MP}$ ) overestimated SOC sequestration (0.4 Mg C ha $\mathrm{Mg}^{-1}\left[400 \mathrm{lb} \mathrm{ac}^{-1} \mathrm{yr}^{-1}\right]$ ) as compared to pretreatment method $(-0.3$ $\left.\mathrm{Mg} \mathrm{C} \mathrm{ha} \mathrm{y}^{-1}\left[-300 \mathrm{lb} \mathrm{ac}^{-1} \mathrm{yr}^{-1}\right]\right)$, where both NT and MP were compared to the same pretreatment baseline. The MP was not at steady state and lost 30\% of the SOC stock in 20 years, while the NT lost $13 \%$. The $17 \%$ difference in NT SOC stock was retention of more SOC stock SOC stocks were larger at the start of the 20-year study than at the end of the study, since the system lost 13\% (figure 3). The $17 \%$ difference can be considered as $\mathrm{C}$ retention since the NT system is still losing SOC as part of its dynamic.

\section{CONCLUSIONS AND RECOMMENDATIONS}

Previous soil science research has built an essential foundation to assess the capacity of soil to store and sequester than that in MP. The NT pretreatment 


\section{Figure 3}

Soil organic carbon (SOC) stock changes from the pretreatment baseline and after 20 years on the moldboard plow (MP) and no-tillage (NT) plots with depth.

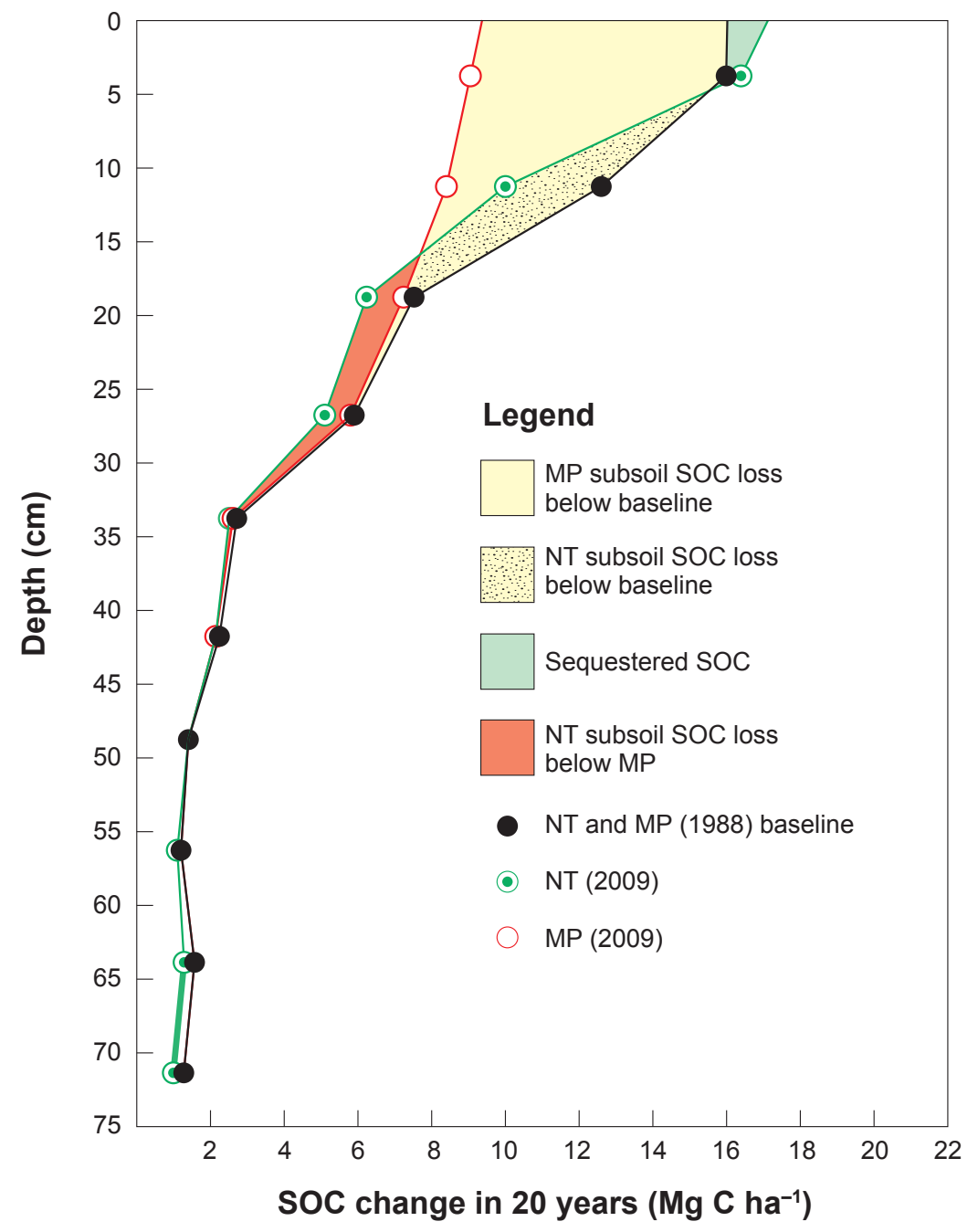

C. However, there are inconsistencies and errors in the application of SOC sequestration concept and plot area experiment designs methods used to determine SOC sequestration rate. The most critical consideration in determining SOC sequestration is the adherence to a standard definition or concept of SOC sequestration, which is based on the capture of atmospheric $\mathrm{CO}_{2}$ by the land unit soil ecosystem. It is important to determine SOC sequestration rates for a range of agricultural land treatments and to establish a protocol to validate the rate of SOC sequestration.
It is thus proposed that field experimental methods and procedures be selected to more carefully measure, monitor, and assess internal and external inputs. The amount of SOC loss from the soil storage during the time of experiment needs to be subtracted from SOC sequestration amount to determine the change in net SOC storage. The proposed protocols that have been discussed above are critical to move the science forward and to attempt to address the role of soil (as a source or sink) in future climate trends. The amount of SOC sequestered as a result of alternative agricultural systems such as NT and its effects on the net SOC storage changes in terrestrial C pool and SOC released to the water and atmospheric pools need to be identified. If the losses from the terrestrial $\mathrm{C}$ pool are greater than the gains in SOC during the time of the experiment, then no net SOC sequestration would have occurred and the release of $\mathrm{CO}_{2}$ to atmosphere would have increased. Additional research investments are warranted to better understand agricultural management practices that are most likely to sequester SOC, or at least retain net SOC over time, and can create a positive soil $\mathrm{C}$ budget.

It is recommend that (1) the protocol for measuring SOC sequestration be standardized; (2) sequestration rates over a period of time be measured and compared to the baseline over regular intervals during the study; (3) long-term studies be designed and managed for SOC measurements using a standard protocol and should include soil sampling during the nongrowing season time; (4) analyses account for inputs of extraneous $\mathrm{C}$ input into the land unit; and (5) when using an existing long-term tillage study that is lacking pretreatment baseline to determine SOC sequestration rates, the study be paused and a pretreatment SOC stock be established for future SOC sequestration determination. Any SOC sequestration rates determined before pretreatment SOC stock measurements cannot be verified. However, any future calculated SOC sequestration rates can be validated and published.

\section{REFERENCES}

Baker, J.M., T.E. Ochsner, R.T. Venterea, and T.J. Griffis. 2007. Tillage and soil carbon sequestration-what do we really know? Agriculture, Ecosystems and Environment 118:1-5.

Blanco-Canqui, H., and R. Lal. 2008. No-tillage and soil-profile carbon sequestration: An on farm assessment. Soil Science Society of America Journal 72:693-701, doi:10.2136/sssaj2007.0233.

Casta Junior, C., M. Corbeels, M. Bernox, M.C. Bernox, M.C. Piccolo, M. Piccolo, M. Siqueira Neto, B.J. Feigl, C.E.P Cerri, C.C. Cerro, E. Scopel, and R. Lal. 2013. Assessing soil carbon storage rates under not-tillage: Comparing the synchronic and diachronic approaches. Soil and Tillage Research 134:2017-212.

Franzluebbers, A.J. 2010. Achieving soil organic carbon sequestration with conservation agricultural 
systems in the southeastern United States. Soil Science Society of America Journal 74:347-357.

Franzluebbers, A.J., and R.F. Follett. 2005. Greenhouse gas contributions and mitigation potential is agricultural region of North America. Soil Tillage Research 83:25-52.

Gregorich, E.G., P. Rochette, A.J.VandenBygaart, and D.A. Angers. 2005. Greenhouse gas contributions of agricultural soils and potential mitigation practices in eastern Canada. Soil Tillage Research 83:73-94.

Huggins, D.R., R.R.Allmaras, C.E. Clapp, J.A. Lamb, and G.W. Randall. 2007. Corn-soybean sequence and tillage effects on soil carbon dynamics and storage. Soil Science Society of America Journal 71:145-154.

Janzen, H.H. 2006. The soil carbon dilemma: Shall we hoard it or use it? Soil Biology and Biochemistry 38(3):419-424.

Johnson, J.M.F., D.C. Reicosky, R.R. Allmaras, T.J. Sauer, R.T. Venterea, and C.J. Dell. 2005. Greenhouse gas contributions and mitigation potential of agriculture in the central USA. Soil Tillage Research 83:73-94.

Kumar, S., A. Kadono, R. Lal, and W. Dick. 2012. Long-term no-till impacts on organic carbon and properties of two contrasting soils and corn yields in Ohio. Soil Science Society of America Journal 76:798-809.

Lal, R. 1999. Soil management and restoration for C sequestration to mitigate the accelerated greenhouse effect. Progress in Environmental Science 1:307-326.
Lal, R., J.M. Kimble, R.F. Follett, and C.V. Cole. 1998 The Potential of US Cropland to Sequesters Carbon and Mitigate the Greenhouse Effect. Chelsea, MI: Sleeping Bear Press, Inc. and Ann Arbor Press.

Liebig, M.A., J.A. Morgan, J.D. Reeder. B.H. Ellert, H.T. Gollany, and G.E. Schuman. 2005 Greenhouse gas contributions and mitigation potential of agricultural practices in northwestern USA and western Canada. Soil Tillage Research 83:25-52

Luo, Z., E. Wang, and O.J. Sun. 2010. Can no-tillage stimulate carbon sequestration in agricultural soils? A meta-analysis of paired experiments. Agriculture, Ecosystems, and Environment 139:224-231.

Lyons, D.J., C.A. Mong, R.E. Brown, and A.K. Metherell. 1997. Soil organic matter changes over two decades of winter wheat-fallow cropping in western Nebraska. In Soil Organic Matter in Temperate Agroecosystems: Long-term Experiments in North America, eds. E.A. Paul, K. Paustian, E.T. Elliott, and C.V. Cole. Boca Raton, FL: CRC Press.

Olson, K.R. 2010. Impacts of tillage, slope, and erosion on soil organic carbon retention. Soil Science 175:562-567.

Olson, K.R. 2013. Soil organic carbon sequestration, storage, retention, and loss in US croplands: Issues paper for protocol development. Geoderma 195-196:201-206, doi:org/10.1016/j.geoderma.2012.12.004. http://www.sciencedirect. com/science/article/pii/S0016706112004211.
Olson, K.R., M.M. Al-Kaisi, R. Lal, and B. Lowery. 2014. Experimental consideration, treatments, and methods in determining soil organic carbon sequestration rates. Soil Science Society of America Journal 78(2):348-360, doi: 10.2136/ sssaj2013.09.0412. https://www.soils.org/ publications/sssaj/pdfs/78/2/348.

Sanderman, J., and J. Baldock. 2010. Accounting for soil carbon sequestration in national inventories: A soil scientist's perspective. Environmental Research Letters 5 (Jul-Sep. 2010), doi:10.188/1748-9326/5/3/034003.

Sanford, G.R., J.L. Posner, R.D. Jackson, C.J. Kucharik, J.L. Hedtcke, and T.L. Lin. 2012. Soil carbon lost form Mollisols of the North Central USA with 20 years of agricultural best management practices. Agriculture, Ecosystems and Environment 162:68-72.

Six, J., S.M. Ogle, FJ. Breidt, R.T. Conant, A.R. Mosier, and K. Paustian. 2004. The potential to mitigate global warming with not-tillage management is only realized when practiced in the long term. Global Change Biology 10:155-160.

West, T.O., and W.M. Post. 2002. Soil organic carbon sequestration rates by tillage and crop rotation: A global data analysis. Soil Science Society of America Journal 66:1930-1946. 